Науковий вісник НЛтУ України
Scientific Bulletin of UNFU
https://nv.nltu.edu.ua
$\begin{gathered}\text { https://doi.org/10.15421/40290526 } \\ \text { Article received } 17.05 .2019 \mathrm{p} .\end{gathered}$
$\begin{gathered}\text { Article accepted } 30.05 .2019 \mathrm{p} . \\ \text { Удк } 536.24\end{gathered}$

В. І. Гавриш, О. С. Король, І. Г. Козак, О. В. Куспиш, В. Ю. Майхер

Національний університет "Львівська політехніка", м. Львів, Україна

\title{
МАТЕМАТИЧНА МОДЕЛЬ АНАЛІЗУ ТЕПЛООБМІНУ МІЖ ДВОШАРОВОЮ ПЛАСТИНОЮ 3 ЛОКАЛЬНО ЗОСЕРЕДЖЕНИМ ДЖЕРЕЛОМ ТЕПЛА ТА НАВКОЛИШНІМ СЕРЕДОВИЩЕМ
}

\begin{abstract}
Розроблено математичну модель аналізу теплообміну між ізотропною двошаровою пластиною, яка нагрівається точковим джерелом тепла, зосередженим на поверхнях спряження шарів, і навколишнім середовищем. Для цього 3 використанням теорії узагальнених функцій коефіцієнт теплопровідності матеріалів шарів пластини зображено як єдине ціле для всієї системи. 3 огляду на це, замість двох рівнянь теплопровідності для кожного із шарів пластини та умов ідеального теплового контакту, між ними отримано одне рівняння теплопровідності в узагальнених похідних із сингулярними коефіцієнтами. Для розв'язування крайової задачі теплопровідності, що містить це рівняння та крайові умови на межових поверхнях пластини, використано інтегральне перетворення Фур'є і внаслідок отримано аналітичний розв'язок задачі в зображеннях. До цього розв'язку застосовано обернене інтегральне перетворення Фур'є, яке дало змогу отримати остаточний аналітичний розв'язок вихідної задачі. Отриманий аналітичний розв'язок подано у вигляді невласного збіжного інтегралу. За методом Сімпсона отримано числові значення цього інтегралу з певною точністю для заданих значень товщини шарів, просторових координат, питомої потужності точкового джерела тепла, коефіцієнта теплопровідності конструкційних матеріалів пластини та коефіцієнта тепловіддачі з межових поверхонь пластини. Матеріалом першого шару пластини $є$ мідь, а другого - алюміній. Для визначення числових значень температури в наведеній конструкції, а також аналізу теплообміну між пластиною та навколишнім середовищем, зумовленим різними температурними режимами завдяки нагріванню пластини точковим джерелом тепла, зосередженим на поверхнях спряження шарів, розроблено обчислювальні програми. Із використанням цих програм наведено графіки, що відображають поведінку кривих, побудованих із використанням числових значень розподілу температури залежно від просторових координат. Отримані числові значення температури свідчать про відповідність розробленої математичної моделі аналізу теплообміну між двошаровою пластиною з точковим джерелом тепла, зосередженим на поверхнях спряження шарів і навколишнім середовищем, реальному фізичному процесу. Програмні засоби також дають змогу аналізувати такого роду неоднорідні середовища щодо їх термостійкості під час нагрівання. Як наслідок, стає можливим іiї підвищити і захистити від перегрівання, яке може спричинити руйнування не тільки окремих елементів, а й всієї конструкції.

Ключові слова: теплообмін; ізотропна двошарова пластина; теплопровідність; температурне поле; теплоізольована поверхня; ідеальний тепловий контакт.
\end{abstract}

Вступ. Процеси теплообміну і пов'язаного з ним масообміну мають велике значення для інтенсифікації теплоенергетичних, енерготехнологічних і хіміко-технологічних процесів у промисловості 3 високою ефективністю і відіграють винятково важливу роль у природі та техніці. Від них залежить температурний режим навколишнього середовища та житлових приміщень, вони визначають здійснення робочого процесу в різних технологічних установках тощо. Тому і недивно, що теорія теплообміну інтенсивно розвивалась, особливо в останні десятиріччя 3 огляду на потреби теплоенергетики, атомної енергетики, космонавтики та деяких інших галузей техніки. Зараз розробляють способи теплового

захисту високошвидкісних літальних установок, зокрема космічних багаторазової дії, в активних зонах реакторів, у магнітогідродинамічних генераторах (установках для прямого перетворення теплоти в електричну енергію), у газотурбінних установках. Для техніки низьких температур досліджують процеси теплообміну, зокрема в установках із використанням ефекту надпровідності, наприклад у магнітах, які створюють значні магнітні поля. Тривають роботи зі створення кріохірургічних інструментів, які використовують для операцій зі швидким заморожуванням окремих ділянок живої тканини. Прогрес у цій галузі значно пов'язаний із правильною організацією процесів теплообміну як у само-

\section{Інформація про авторів:}

Гавриш Василь Іванович, д-р техн. наук, професор, кафедра програмного забезпечення.

Email: gavryshvasyl@gmail.com; https://orcid.org/0000-0003-3092-2279

Король Олександр Сергійович, ст. викладач, кафедра фізичного виховання. Email: korol_lofkk@i.ua

Козак Іван Герасимович, ст. викладач, кафедра фізичного виховання. Email: gavryshvasyl@gmail.com

Куспиш Олександр Володимирович, викладач, кафедра фізичного виховання. Email: Pysanka@ukr.net

Майхер Вікторія Юріївна, канд. техн. наук, асистент, кафедра програмного забезпечення. ilkanych.vika@gmail.com

Цитування за ДСтУ: Гавриш В. І., Король О. С., Козак І. Г., Куспиш О. В., Майхер В. Ю. Математична модель аналізу теплообміну між двошаровою пластиною з локально зосередженим джерелом тепла та навколишнім середовищем. Науковий вісник НЛтУ України. 2019, т. 29, № 5. С. 129-133.

Citation APA: Havrysh, V. I., Korol, O. S., Kozak, I. G., Kuspish, O. V., \& Maikher, V. U. (2019). Mathematical model for determination analysis between two-solid plate with a local between thermal source and the environment. Scientific Bulletin of UNFU, 29(5), 129133. https://doi.org/10.15421/40290526 
му інструменті, так і в тканині. Виконують роботи зі створення установок для сублімаційного сушіння деяких продуктів харчування, успішне розроблення яких залежить від правильної організації процесів сублімації та десублімації. Удосконалюються методи дослідження процесів теплообміну на Землі та в її атмосфері, зокрема прогнозування погоди. Запити різних галузей промисловості стимулюють сталий і швидкий розвиток наукових досліджень у галузі теплообміну. Важко назвати якусь галузь, в якій би розв'язки задач теплопровідності не мали істотного теоретичного, практичного та економічного значення. Вони поширені як у космічній, авіаційній, електронній, електротехнічній галузях, так і в сучасному зварювальному виробництві, цифрових технологіях, під час дослідження геотемпературних полів.

Аналіз останніх досліджень та публікацій. Визначення температурних режимів як в однорідних, так і в неоднорідних конструкціях привертає увагу багатьох дослідників (Carpinteri \& Paggi, 2008; Noda, 1991; Otao, Tanigawa \& Ishimaru, 2000; Tanigawa, Akai \& Kawamura, 1996; Tanigawa \& Otao, 2002; Yangian \& Daihui, 2009).

У роботі (Turii, 2008) досліджено теплообмін у шаруватій пластині зі складниками різної прозорості, з'єднаними тонким проміжним шаром за теплового опромінення з боку частково прозорого шару. За допомогою ефективного коефіцієнта відбивання на поверхні контакту отримано наближені співвідношення для визначення поля випромінювання в основному частково прозорому шарі.

Виконано зовнішній асимптотичний розклад розв'язку нестаціонарної задачі теплопровідності для шаруватої анізотропної пластини з крайовими умовами другого роду на лицьових поверхнях. Проаналізовано отримані двовимірні диференціальні рівняння та досліджено асимптотичні властивості розв'язків задачі. Отримано оцінки точності, з якою розподіл температури поза межовим шаром пластини вважають кусково-лінійною або кусково-квадратичною функцією за товщиною $(\mathrm{Ne}-$ mirovskii \& Iankovskii, 2007). У працях (Havrysh \& Fedasjuk, 2012; Havrysh, Baranetskiy \& Kolyasa, 2018; Havrysh, Kolyasa \& Ukhanska, 2019) удосконалено існуючі та розроблено нові підходи до створення математичних моделей аналізу теплообміну між кусково-однорідними конструкціями та навколишнім середовищем і методів розв'язування лінійних і нелінійних крайових задач для кусково-однорідних середовищ. Розглянуто дво- та тривимірні моделі, що містять рівняння, коефіцієнти яких є функціями теплофізичних властивостей фаз і геометричної структури. Наведено методи визначення аналітичних та аналітично-числових розв'язків крайових задач теплопровідності. Досліджено та проаналізовано теплообмінні процеси в однорідних та шаруватих конструкціях із чужорідними включеннями канонічної форми. У роботах (Podstrigach, Lomakin \& Koliano, 1984; Koliano, 1992) наведено загальні рівняння теплопровідності для неоднорідних середовищ.

Огляд основних літературних джерел показав, що малодослідженими та не розробленими залишилися моделі, які б враховували кусково-однорідну структуру конструкцій, які функціонують за інтенсивних температурних збуреннях, зумовлених локально зосередженими джерелами тепла. Це приводить до розроблення математичних моделей аналізу теплообмінних процесів у елементах складних електронних і електромеханічних систем, які геометрично описують шаруватими середовищами. Результати досліджень теплообміну в таких конструкціях використовують надалі для проектування наведених систем щодо їх термостійкості.

Метою дослідження є розроблення математичної моделі аналізу теплообміну двошарової пластини з навколишнім середовищем, зумовленим точковим джерелом тепла, зосередженим на поверхнях спряження шарів, що дасть змогу підвищити точність визначення теплообміну між шаруватими конструкціями та навколишнім середовищем, ефективність методів проектування складних систем.

Об'єкт дослідження та його математична модель. Розглянемо ізотропну відносно теплофізичних параметрів двошарову пластину товщиною $2 \delta$ з теплоізольованими лицевими поверхнями $|z|=\delta$, яка складається із двох різнорідних шарів, що відрізняються геометричними (шириною) та теплофізичними (коефіцієнтом теплопровідності) параметрами, віднесену до декартової прямокутної системи координат $(x, y, z)$. Початок іiі, де зосереджено точкове джерело тепла 3 потужністю $q_{0}=$ const,$\quad$ вибрано на поверхні спряження шарів $K_{0}=\{(x, 0, z):|x|<\infty,|z| \leq \delta\}$, на якій існує ідеальний тепловий $\quad$ контакт $t_{1}(x, y)=t_{2}(x, y), \lambda_{1} \frac{\partial t_{1}(x, y)}{\partial y}=\lambda_{2} \frac{\partial t_{2}(x, y)}{\partial y}$

$y=0$ (1,2 - для першого та другого шарів пластини відповідно). На межових поверхнях

$K_{1}=\left\{\left(x,-y_{1}, z\right):|x|<\infty,|z| \leq \delta\right\}$ та $K_{2}=\left\{\left(x, y_{2}, z\right):|x|<\infty,|z| \leq \delta\right\}$ пластини задано умови конвективного теплообміну 3 навколишнім середовищем згідно зі законом Ньютона (рис. 1).

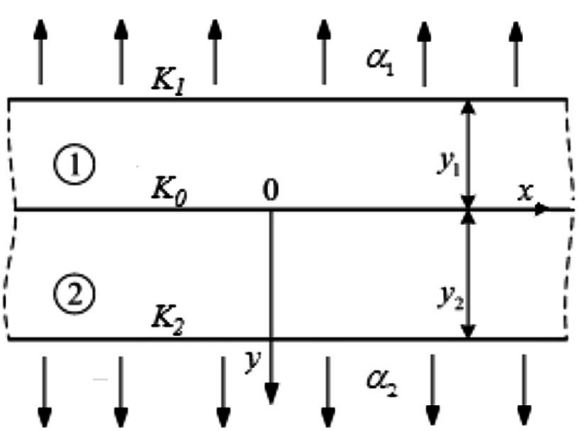

Рис. 1. Переріз ізотропної пластини з тепловіддачею площиною $z=0$

У наведеній структурі потрібно визначити розподіл температури $t(x, y)$ за просторовими координатами, який отримуємо, розв'язавши рівняння теплопровідностi (Podstrigach, Lomakin \& Koliano, 1984; Koliano, 1992)

$$
\lambda(y) \frac{\partial^{2} t}{\partial x^{2}}+\frac{\partial}{\partial y}\left[\lambda(y) \frac{\partial t}{\partial y}\right]=-q_{0} \delta(x, y)
$$

3 крайовими умовами

$$
\left.t\right|_{|x| \rightarrow \infty}=t_{c},\left.\lambda_{1} \frac{\partial t}{\partial y}\right|_{y=-y_{1}}=\alpha_{1}\left(t-t_{c}\right),\left.\lambda_{2} \frac{\partial t}{\partial y}\right|_{y=y_{2}}=-\alpha_{2}\left(t-t_{c}\right),
$$

де: $\lambda(y)$ - коефіцієнт теплопровідності неоднорідної пластини, його можна визначити

$$
\lambda(y)=\lambda_{1}+\left(\lambda_{2}-\lambda_{1}\right) S_{+}(y)
$$

де: $\lambda_{1}$ і $\lambda_{2}-$ коефіцієнти теплопровідності матеріалів 1го та 2-го шарів пластини відповідно; $t_{c}$ - температура навколишнього середовища; $\alpha_{1}$ i $\alpha_{2}$ - коефіцієнти теп- 
ловіддачі з поверхонь $K_{1}$ і $K_{2}$ відповідно; $S_{+}(\zeta)-$ асиметрична одинична функція (Korn, \& Korn, 1977),

$$
S_{+}(\zeta)= \begin{cases}1, & \zeta>0 \\ 0, & \zeta \leq 0\end{cases}
$$

$\delta(\zeta)=d S(\zeta) / d \zeta$ - дельта-функція Дірака; $S(\zeta)$ - симетрична одинична функція,

$$
S(\zeta)= \begin{cases}1, & \zeta>0 \\ 0,5, & \zeta=0 \\ 0, & \zeta<0\end{cases}
$$

Введемо функцію

$$
T(x, y)=\lambda(y) \theta(x, y)
$$

і продиференціюємо їі за змінними $x$ та $y$ з урахуванням виразу для коефіцієнта теплопровідності $\lambda(y)$ (3). Внаслідок таких дій отримаємо

$$
\lambda(y) \frac{\partial \theta}{\partial y}=\frac{\partial T}{\partial y}-\left.\left(\lambda_{2}-\lambda_{1}\right) \theta\right|_{y=0} \delta_{+}(y) ; \lambda(y) \frac{\partial \theta}{\partial x}=\frac{\partial T}{\partial x},
$$

де: $\quad \theta(x, y)=t(x, y)-t_{c} \quad-\quad$ збиткова температура; $\delta_{+}(\zeta)=d S_{+}(\zeta) / d \zeta-$ асиметрична дельта-функція Дірака (Korn, \& Korn, 1977).

Підставивши вирази (5) у співвідношення (1), одержимо диференціальне рівняння 3 частковими похідними із сингулярними коефіцієнтами

$$
\Delta T-\left.\left(\lambda_{2}-\lambda_{1}\right) \theta\right|_{y=0} \delta_{+}^{\prime}(y)=-q_{0} \delta(x, y),
$$

де $\Delta$ - оператор Лапласа в декартовій прямокутній системі координат, $\Delta=\frac{\partial^{2}}{\partial x^{2}}+\frac{\partial^{2}}{\partial y^{2}}$.

Отже, шукане температурне поле в наведеній системі цілком визначається рівнянням (6) із крайовими умовами (2).

Аналітичний розв'язок. Застосувавши інтегральне перетворення Фур'є за координатою $x$ до рівняння (6) i крайових умов (2) з урахуванням співвідношення (4), приходимо до звичайного диференціального рівняння зі сталими коефіцієнтами

$$
\frac{d^{2} \bar{T}}{d y^{2}}-\xi^{2} \bar{T}=\left.\left(\lambda_{2}-\lambda_{1}\right) \bar{\theta}\right|_{y=0} \delta_{+}^{\prime}(y)-\frac{q_{0}}{\sqrt{2 \pi}} \delta(y)
$$

3 крайовими умовами

$$
\left.\frac{\partial \bar{T}}{\partial y}\right|_{y=-y_{1}}=\left.\frac{\alpha_{1}}{\lambda_{1}} \bar{T}\right|_{y=-y_{1}},\left.\frac{\partial \bar{T}}{\partial y}\right|_{y=y_{2}}=-\left.\frac{\alpha_{2}}{\lambda_{2}} \bar{T}\right|_{y=y_{2}},
$$

де: $\bar{T}(y) \quad-\quad$ трансформанта функції $T(x, y)$; $\bar{T}(y)=\frac{1}{\sqrt{2 \pi}} \int_{-\infty}^{\infty} e^{i \xi x} T(x, y) d \xi ; \quad \xi-$ параметр інтегрального перетворення Фур'є, $i^{2}=-1$.

Загальний розв'язок рівняння (7) знайдемо за допомогою методу варіації сталих у вигляді

$$
\bar{T}(y)=c_{1} e^{\xi y}+c_{2} e^{-\xi y}+\left.\left(\lambda_{2}-\lambda_{1}\right) \bar{\theta}\right|_{y=0} \operatorname{ch} \xi y S_{+}(y)-\frac{q_{0}}{\xi \sqrt{2 \pi}} \operatorname{sh} \xi y S(y),(9)
$$

де $c_{1}, c_{2}$ - сталі інтегрування.

Величину $\left.\bar{\theta}\right|_{y=0}$ визначаємо з виразу (9) у вигляді

$$
\left.\bar{\theta}\right|_{y=0}=\frac{c_{1}+c_{2}}{\lambda_{1}} .
$$

Використавши крайові умови (8) для визначення сталих інтегрування, отримаємо розв'язок задачі (7) і (8), а саме

$$
\bar{T}(y)=\frac{q_{0}}{\xi \sqrt{2 \pi}}\left[\frac{1}{D}\left(\bar{T}_{1}(y)+\bar{T}_{2}(y) \bar{T}_{3}(y)\right)-\operatorname{sh} \xi y S(y)\right],
$$

де:

$$
\bar{T}_{1}(y)=\operatorname{ch} \xi\left(y+y_{1}\right)+\frac{\alpha_{1}}{\lambda_{1} \xi} \operatorname{sh} \xi\left(y+y_{1}\right)
$$

$$
\bar{T}_{2}(y)=\left(K_{\lambda}-1\right)\left(\operatorname{ch} \xi y_{1}+\frac{\alpha_{1}}{\lambda_{1} \xi} \operatorname{sh} \xi y_{1}\right) \operatorname{ch} \xi y S_{+}(y) ;
$$

$$
\bar{T}_{3}(y)=\operatorname{ch} \xi y_{2}+\frac{\alpha_{2}}{\lambda_{2} \xi} \operatorname{sh} \xi y_{2} ;
$$

$$
\begin{gathered}
D=\left(K_{\lambda}-1\right)\left(\operatorname{ch} \xi y_{1}+\frac{\alpha_{1}}{\lambda_{1} \xi} \operatorname{sh} \xi y_{1}\right)\left(\operatorname{sh} \xi y_{2}+\frac{\alpha_{2}}{\lambda_{2} \xi} \operatorname{ch} \xi y_{2}\right)+D_{1} ; \\
D_{1}=\left(1+\frac{\alpha_{1} \alpha_{2}}{\lambda_{1} \lambda_{2} \xi^{2}}\right) \operatorname{sh} \xi\left(y_{1}+y_{2}\right)+\frac{1}{\xi}\left(\frac{\alpha_{1}}{\lambda_{1}}+\frac{\alpha_{2}}{\lambda_{2}}\right) \operatorname{ch} \xi\left(y_{1}+y_{2}\right),
\end{gathered}
$$

$K_{\lambda}=\lambda_{2} / \lambda_{1}-$ коефіцієнт, який характеризує відносну теплопровідність шарів пластини.

Застосувавши обернене інтегральне перетворення Фур'є до співвідношення (10), одержимо розв'язок задачі (1) і (2) у вигляді

$$
T(x, y)=\frac{q_{0}}{\pi} \int_{0}^{\infty} \frac{\cos \xi x}{\xi}\left[\frac{1}{\Delta}\left(\bar{T}_{1}(y)+\overline{T_{2}}(y) \overline{T_{3}}(y)\right)-\operatorname{sh} \xi y S(y)\right] d \xi .
$$

Отже, шукане температурне поле у двошаровій пластині, зумовлене зосередженим на поверхнях спряження шарів пластини точковим джерелом тепла, виражено формулою (11), з якої отримуємо значення температури в довільний точці наведеної конструкції.

Аналіз числових результатів. Виконали числовий аналіз температури $\theta(x, y)$ у двошаровій пластині для таких вихідних даних: матеріали пластини - мідь ( $\lambda_{1}=395$ вт/(м·град) за температури $t=20^{\circ} \mathrm{C}$ ) для першого шару та алюміній ( $\lambda_{2}=207$ вт/(м·град) за температури $t=27{ }^{\circ} \mathrm{C}$ ) для другого (Kikoin, 1976); $y_{1}=y_{2}=1 \mathrm{M} ; q_{0}=200$ вт. Числові обчислення проведено 3 точністю $\varepsilon=10^{-6}$.

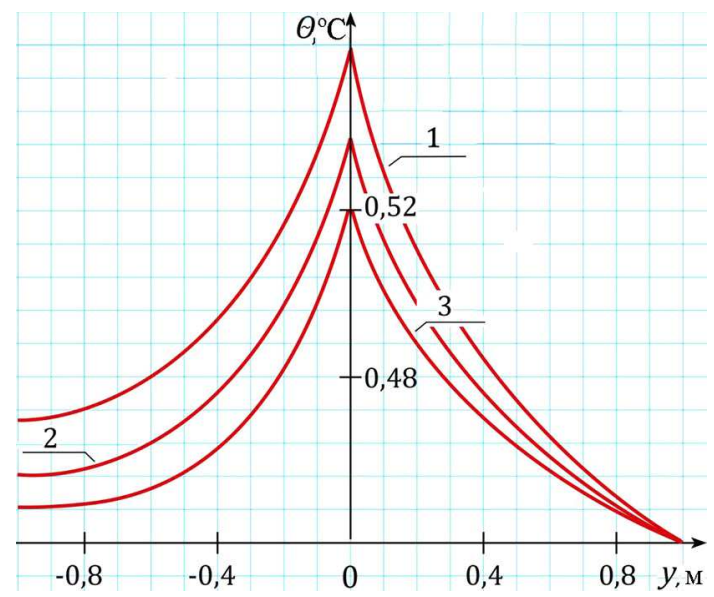

Рис. 2. Залежність температури $\theta(x, y)$ від координати у для $\mathrm{x}=0$ та заданих значень коефіцієнта тепловіддачі: крива 1 $\alpha_{1}=\alpha_{2}=17,64$ вт/(м².град); крива $2-\alpha_{1}=\alpha_{2}=15,74$

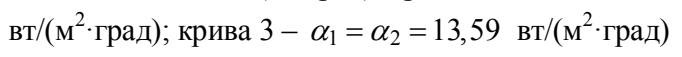

Проілюстрували (рис. 2) зміну температури $\theta(x, y)$ залежно від просторової координати $y$ для $x=-2$ та заданих значень коефіцієнта тепловіддачі. Із поведінки кривих видно, що температура, як функція координати $y$, монотонно зростає у першому шарі пластини і досягає максимальне значення в точці $(0 ; 0)$, в якій зосереджено точкове джерело тепла, а в другому шарі пластини вона монотонно спадає. Найменші значення у цьому випадку температура досягає на межових поверхнях $K_{1}, K_{2}$ пластини. Як видно із графіків, коефіцієнти тепловіддачі 
значно впливають на розподіл температури, причому вона $є$ вищою у першому шарі, оскільки матеріалом цього шару є мідь і коефіцієнт теплопровідності є більшим від коефіцієнта теплопровідності для другого шару, матеріалом якого є алюміній.

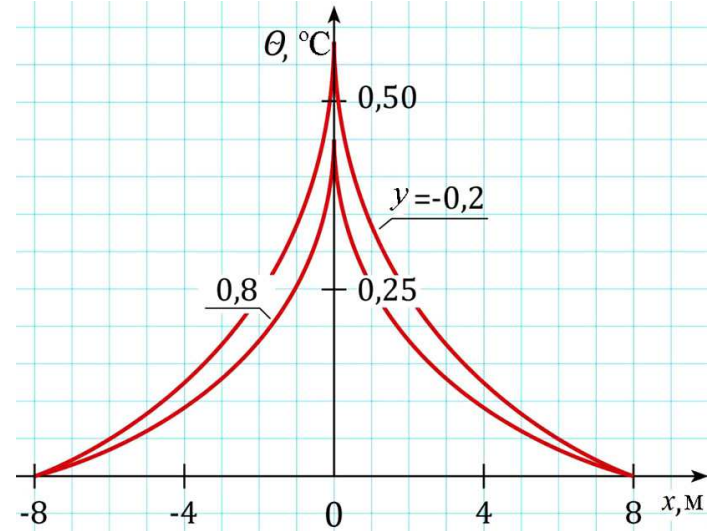

Рис. 3. Залежність температури $\theta(x, y)$ від координати $x$ для $\alpha_{1}=\alpha_{2}=16,92$ вт/(м·град) та заданих значень координати $y$

На рис. 3 зображено зміну температури $\theta(x, y)$ залежно від просторової координати $x$ та заданих значень просторової координати $y$. Із поведінки кривих видно, що температура, як функція координати $x$, є достатньо гладкою та монотонною функцією і досягає максимального значення в точці $(0 ; 0)$. У разі збільшення за абсолютною величиною значень просторової координати $x$ температура знижується, що свідчить про адекватність математичної моделі реальному фізичному процесу.

Висновки. Із використанням узагальнених функцій та інтегрального перетворення Фур'є для двошарової пластини з точковим джерелом тепла та тепловіддачею побудовано аналітичний розв'язок крайової задачі теплопровідності, диференціальне рівняння якої містить розривні та сингулярні коефіцієнти. Цей розв'язок подано у вигляді невласного збіжного інтегралу. Із його використанням розроблено алгоритм і розрахункову програму для визначення температурного поля в довільній точці двошарової пластини з точковим джерелом тепла, зосередженим на поверхні спряження шарів.

На цій основі отримано числові значення температурного поля, із використанням яких побудовано графіки, де зображено криві, які відображають поведінку температури залежно від просторових координат та значень коефіцієнта тепловіддачі $з$ межових поверхонь пластини. Це дає змогу аналізувати теплообмін у неоднорідних шаруватих середовищах щодо їх термостійкості під час нагрівання та захистити їх від перегрі- вання, яке може спричинити руйнування не тільки окремих елементів, а й всієї конструкції.

\section{Перелік використаних джерел}

Carpinteri, A., \& Paggi, M. (2008). Thermoelastic mismatch in nonhomogeneous beams. J. Eng. Math., 61(2-4), 371-384. https://doi.org/10.1007/s10665-008-9212-8

Havrysh, V. I., \& Fedasjuk, D. V. (2012). Modelling of temperature regimes in piecewise-homogeneous structures. Lviv: Publishing house of Lviv Politechnic National University, $176 \mathrm{p}$.

Havrysh, V. I., Baranetskiy, Ya. O., \& Kolyasa, L. I. (2018). Investigation of temperature modes in thermosensitive non-uniform elements of radioelectronic devices. Radio electronics, computer science, management, 3(46), 7-15.

Havrysh, V. I., Kolyasa, L. I., \& Ukhanka, O. M. (2019). Determination of temperature field in thermally sensitive layered medium with inclusions. Scientific Bulletin of the National Chemical University, 1, 94-100.

Kikoin, I. K. (Ed.). (1976). Tablitcy fizicheskikh velichin. Moscow: Atomizdat, 1008 p. [In Russian].

Koliano, Iu. M. (1992). Metody teploprovodnosti i termouprugosti neodnorodnogo tela. Kyiv: Scientific thought, 280 p. [In Russian].

Korn, G., \& Korn, T. (1977). Spravochnik po matematike dlia nauchnykh rabotnikov i inzhenerov. Moscow: Science, 720 p. [In Russian].

Nemirovskii, Iu. V., \& Iankovskii, A. P. (2007). Asimptoticheskii analiz zadachi nestatcionarnoi teploprovodnosti sloistykh anizotropnykh neodnorodnykh plastin pri granichnykh usloviiakh pervogo i tretego roda na litcevykh poverkhnostiakh. Mat. metodi ta fiz.mekh. polia, 50(2), 160-175. [In Russian].

Noda, N. (1991). Thermal stresses in materials with temperature-dependent properties. Appl. Mech. Rev., 44, 383-397. https://doi.org/10.1115/1.3119511

Otao, Y., Tanigawa, O., \& Ishimaru, O. (2000). Optimization of material composition of functionality graded plate for thermal stress relaxation using a genetic algorithm. J. Therm. Stresses, 23, 257-271. https://doi.org/10.1080/014957300280434

Podstrigach, Ia. S., Lomakin, V. A., \& Koliano, Iu. M. (1984). Termouprugost tel neodnorodnoi struktury. Moscow: Science, 368 p. [In Russian].

Tanigawa, Y., \& Otao, Y. (2002). Transient thermoelastic analysis of functionally graded plate with temperature-dependent material properties taking into account the thermal radiation. Nihon Kikai Gakkai Nenji Taikai Koen Ronbunshu, 2, 133-134.

Tanigawa, Y., Akai, T., \& Kawamura, R. (1996). Transient heat conduction and thermal stress problems of a nonhomogeneous plate with temperature-dependent material properties. J. Therm. Stresses, 19(1), 77-102. https://doi.org/10.1080/01495739608946161

Turii, O. (2008). Neliniina kontaktno-kraiova zadacha termomekhaniky dlia oprominiuvanoi dvosharovoi plastyny, ziednanoi promizhkovym sharom. Fizyko-matematychne modeliuvannia ta informatsiini tekhnolohii, 8, 118-132. [In Ukrainian].

Yangian, Xu., \& Daihui, Tu. (2009). Analysis of steady thermal stress in a $\mathrm{ZrO} 2 / \mathrm{FGM} / \mathrm{Ti}-6 \mathrm{Al}-4 \mathrm{~V}$ composite ECBF plate with temperature-dependent material properties by NFEM. 2009-WASE Int. Conf. on Informa. Eng., 2-2, 433-436.

\section{I. Havrysh, O. S. Korol, I. G. Kozak, O. V. Kuspish, V. U. Maikher Lviv Polytechnic National University, Lviv, Ukraine}

The authors have developed the mathematical model of the heat transfer analysis between an isotropic two-layer plate, which is heated by a point source of heat, concentrated on the surfaces of conjugation of layers and the environment. For this purpose, the coefficient of thermal conductivity of materials of the plate layers is depicted as a single whole for the whole system using the theory of generalized functions. In this connection, instead of the two heat equations for each of the plate layers and the conditions of the ideal thermal contact between them, one equation of heat conductivity in generalized derivatives with singular coefficients is obtained. To solve the boundary value of the thermal conductivity containing this equation and boundary conditions on the boundary surfaces of the plate, the Fourier integral transformation is used, which results in an analytical solution of the problem in the images. To this solution, the inverse Fourier transform has been used, which allowed obtaining the final analytic solution of the original problem. The obtained analytical solution is presented as an inappropriate convergent integral. Numerical values of this integral with certain accu- 
racy for given values of layer thickness, spatial coordinates, specific power of point heat source, coefficient of thermal conductivity of structural materials of a plate and coefficient of heat transfer from boundary surfaces of a plate are obtained by applying the Simpson method. The material of the first layer of the plate is copper, and the second is aluminium. To determine the numerical values of the temperature in the above design, as well as the analysis of the heat transfer between the plate and the environment caused by different temperature regimes due to the heating of the plate by a point source of heat, concentrated on the surfaces of the conjugation of the layers, computational programs were developed. Using these programs, graphs representing the behaviour of curves constructed from the use of numerical values of temperature distribution, depending on spatial coordinates, are presented. The obtained numerical values of temperature testify to the correspondence of the developed mathematical model of the heat exchange analysis between a two-layer plate with a point source of heat, concentrated on the surfaces of the conjugation of the layers and the environment to the real physical process. Software tools also provide an opportunity to analyse such heterogeneous environments as to their thermal stability when heated. As a result, it becomes possible to increase it and thus protect from overheating, which can cause destruction of both individual elements, and the entire design as a whole.

Keywords: heat exchange; isotropic double-layer plate; thermal conductivity; temperature field; heat-insulated surface; perfect thermal contact. 